\title{
IIIS:
}

\section{EXTRATO DE ALHO NA QUEBRA DE DORMÊNCIA DE RIZOMAS DE GENGIBRE (Zingiber officinale)}

\section{GARLIC EXTRACT IN BREAKING DORMANCE OF GINGER RHIZOMES (Zingiber officinale)}

\author{
$1^{*}$ Rafael Zaager. \\ ${ }^{1}$ João Nacir Colombo. \\ ${ }^{1}$ Fabiano Schulz Lauvers. \\ ${ }^{1}$ Geovane Schulz Lauvers. \\ ${ }^{2}$ Marcelo Rodrigo Krause.
}

\begin{abstract}
${ }^{1}$ Instituto Federal do Espírito Santo, IFES, campus Santa Teresa, ES, Brasil. (rafaelzaager@gmail.com). ${ }^{2}$ Universidade Federal de Viçosa, UFV, Viçsoa, MG, Brasil. (agro.krause@gmail.com).

*Autor de correspondência
\end{abstract}

Artigo submetido em 11/08/20, aceito em 20/10/2020 e publicado em 28/12/2020.

Resumo: Em uma produção mais sustentável, visa-se a redução do uso de substâncias sintéticas na olericultura. Nesse sentido, objetivou-se avaliar o uso do extrato de alho na quebra de dormência de rizomas de gengibre. Rizomas de gengibre foram expostas ao extrato de alho em uma concentração de 5\% por 0 horas (T1); 4 horas (T2); 8 horas (T3); 12 horas (T4) e 16 horas (T5). Para melhor absorção do extrato, acrescentou-se na mistura $2 \%$ de óleo mineral. Após o tratamento, as mudas foram distribuídas a cada 0,3 m em sulcos espaçados de 1,0 m. Quando as primeiras mudas começaram a emergir, foi avaliado o índice de velocidade de emergência. Após a emergência dos rizomas, mensalmente foi avaliado o número de caules por metro linear nas duas fileiras úteis de cada unidade experimental. Por ocasião da colheita, foi avaliada a produção das classes de rizomas (rizomas tipo extra e tipo 3). Verificou-se que o emprego do extrato de alho proporcionou resultados positivos para a variável número de caules, em que o maior número por metro $(85,04)$ foi alcançado com a exposição dos rizomas de gengibre ao extrato de alho por 8 horas e 55 minutos. Não houve efeito da utilização do extrato de alho no índice de velocidade de emergência e produção da classe de rizomas tipo extra e tipo 3. Para obtenção de maior número de caules, recomenda-se a exposição dos rizomas de gengibre ao extrato de alho, na concentração de 5\% por um tempo de 8 horas e 55 minutos.

Palavras-chave: dialil dissulfeto; rizomas de gengibre; número de caules propagação vegetativa.

Abstract: In sustainable production systems the aim is to reduce the use of synthetic substances. In this sense, the objective was to evaluate the use of garlic extract in breaking the dormancy of ginger rhizomes. Ginger rhizomes were exposed to garlic extract at a concentration of $5 \%$ for 0 hours (T1); 4 hours (T2); 8 hours (T3); 12 hours (T4) and 16 hours (T5). For better absorption of the extract, 2\% of mineral oil was added to the mixture. After the treatment, the rhizomes were distributed at every $0.3 \mathrm{~m}$ in $1.0 \mathrm{~m}$ spaced furrows. When the first seedlings started to emerge, the emergence speed index was 
evaluated. After the emergence of rhizomes, the number of stems per linear meter was evaluated monthly in the two useful rows of each experimental unit. At harvest, the production of the rhizome classes (extra type and type 3 rhizomes) was evaluated. It was verified that the use of garlic extract provided positive results for the variable number of stems, in which the highest number per meter (85.04) was achieved with the exposure of ginger rhizomes to garlic extract for 8 hours and 55 minutes. There was no effect of the garlic extract use on the emergence speed index and production of the extra type and type 3 rhizomes. In order to obtain a greater number of stems, it is recommended to expose ginger rhizomes to garlic extract at $5 \%$ concentration for a period of 8 hours and 55 minutes.

Keywords: diallyl disulfide; ginger rhizomes; number of stems; vegetative propagation.

\section{INTRODUÇÃO}

A planta de gengibre (Zingiber officinale) pertence à família Zingiberaceae. Produz um rizoma aromático e picante, sendo um dos temperos mais importantes do mundo, apresentando também efeito fitoterápico (ABBAS et al., 2011). Segundo Carmo e Balbino (2015) o uso do gengibre evita enjoos e náuseas sendo recomendado para a digestão de alimentos gordurosos.

No mercado mundial, o negócio referente a cultura totalizou uma receita de US\$ 5,3 bilhões no ano de 2018, sendo produzidas no mesmo período 3,3 milhões de toneladas, representando um aumento da taxa média anual de $6,7 \%$ no período compreendido entre 2007 a 2018 (INDEXBOX, 2019).

A quantidade de gengibre exportado no mundo em 2018 ficou em 564 mil toneladas, destacando-se como maiores exportadores China $(390 \mathrm{mil}$ toneladas), Tailândia (54 mil toneladas), Peru e Índia (21 mil toneladas) e Brasil (15 mil toneladas). Destacam-se como maiores importadores EUA, Japão e Países Baixos (INDEXBOX, 2019).

Segundo Carmo e Balbino (2015), a cultura do gengibre é adaptada a climas quentes e úmidos, produzindo bem em regiões com médias de temperatura entre 25 a $30{ }^{\circ} \mathrm{C}$, além de precipitação mínima de $1.500 \mathrm{~mm} / \mathrm{ano}$. No território Brasileiro, o estado do Espírito Santo, sobretudo a Região Serrana, destaca-se como uma das grandes produtoras. Em 2018, o Estado apresentou um crescimento de 253\% nas exportações, atingindo 9.067 toneladas, representando 59\% do total de exportações do País (FIDELIS, 2018). Foram comercializadas 837,385 toneladas de gengibre nas Centrais de Abastecimento do Espírito Santo (Ceasa), com produção distribuída em vários municípios do estado, destacando-se Santa Leopoldina e Santa Maria de Jetibá (CEASA, 2018).

$\mathrm{O}$ gengibre é propagado normalmente pelos rizomas, que também é a parte comercial usada da planta, acarretando redução do volume comercializado. A micropropagação tem sido empregada para superação dos problemas ocasionados pela propagação via rizomas, garantindo a limpeza clonal e obtenção de um grande número de plantas, uma vez que a propagação por sementes é um problema real devido à má formação de suas flores e sementes (ABBAS et al., 2011).

Nos rizomas de gengibre, as gemas permanecem inaptas à brotação durante certo período, mesmo sob condições adequadas ao seu crescimento, acarretando o inconveniente do atraso no estágio inicial da cultura. Com isso, quando a planta estiver no estágio de desenvolvimento vegetativo terá um período curto para desenvolver todo seu potencial, principalmente devido a fatores climáticos, tal fenômeno é observado também em tubérculos de batata (GERMCHI et al., 2011).

A duração da dormência depende da cultivar, do tempo de maturação, da 
condição de crescimento e do tamanho do tubérculo (GERMCHI et al., 2011). Diante disso, uma das alternativas seria antecipar a emergência e a brotação dos rizomas, possibilitando um rápido desenvolvimento inicial, reduzindo a competição com plantas daninhas, alcançando o máximo desenvolvimento vegetativo, para a partir disso ter acúmulo suficiente de foto assimilados para serem disponibilizados para a formação de novos rizomas.

Para quebra de dormência em tubérculos vários produtos químicos são utilizados, como o ácido giberélico, Tioureia, Etileno, Brometo de metila e Dissulfeto de carbono (GERMCHI et al., 2011). A quebra da dormência dos rizomas para antecipar a colheita é uma alternativa viável para os produtores, entretanto o uso de produtos químicos pode deixar resíduos contaminantes no produto, restringindo oportunidades de exportação principalmente para o mercado europeu.

Por apresentar em sua composição uma substância denominada de dialil dissulfeto, o uso do extrato de alho surge como uma alternativa para a quebra da dormência, uma vez que se trata de um produto natural.

Na literatura não foram encontrados trabalhos que avaliassem o uso do extrato de alho em rizomas de gengibre, porém seu efeito foi verificado em outras espécies. Botelho e Müller (2007) verificaram que o uso do extrato de alho em concentrações entre 1 e $10 \%$ pulverizadas sobre as gemas de macieiras 'Fuji" apresentaram efeito similar ao tratamento convencional com cianamida hidrogenada na quebra de dormência. Botelho (2007) também observou efeito positivo do uso do extrato de alho no estímulo à brotação de gemas de macieiras 'Fuji Kiku’.

$\mathrm{Na}$ perspectiva de buscar alternativas viáveis economicamente, com baixa toxidade e com foco na sustentabilidade ambiental, o extrato de alho por apresentar compostos que favorecem a quebra de dormência, pode ser uma alternativa para ser aplicado em rizomas de gengibre por ocasião do plantio. Diante disso, objetivou-se com este trabalho avaliar o uso do extrato de alho na quebra de dormência de rizomas de gengibre.

\section{MATERIAIS E MÉTODOS}

O experimento foi instalado em condições de campo no período de setembro de 2016 a março de 2017, no distrito de São João do Garrafão, localizado em Santa Maria de Jetibá-ES. Segundo o "Incaper" a precipitação média anual é de $1.390 \mathrm{~mm}$ e as temperaturas variam entre $9,0^{\circ} \mathrm{C}$ e $27,8^{\circ} \mathrm{C}$.

O delineamento experimental adotado foi em blocos casualizados, com cinco tratamentos e quatro repetições. Os tratamentos compreenderam os tempos de exposição dos rizomas de gengibre ao extrato de alho, sendo: T1- 0 horas de exposição (em água pura); T2- 4 horas de exposição; T3- 8 horas de exposição; T412 horas de exposição; T5- 16 horas de exposição. A concentração do extrato de alho e óleo mineral fixada para cada um dos tratamentos foi de $5 \%$ e $2 \%$, respectivamente.

O óleo mineral foi utilizado na mistura para aumentar a absorção do extrato de alho, devido agir dissolvendo as gorduras componentes da cutícula e membranas celulares, eliminando barreiras que diminuem a absorção (EMBRAPA, 2006). Cada unidade experimental foi constituída de duas fileiras com 3,0 m de comprimento, espaçadas em 1,0 m.

Para o preparo do extrato de alho, realizou-se a limpeza e a retirada do envoltório em torno dos bulbilhos. Em seguida, o alho foi triturado. O produto obtido da trituração foi misturado à água, obtendo-se uma concentração de 5\%. Em seguida, os rizomas foram colocados em um recipiente juntamente com a mistura e deixado o tempo equivalente de cada 
tratamento. Os rizomas utilizados foram adquiridos de produtores da região, apresentando comprimento entre 5 a $10 \mathrm{~cm}$ e massa em torno de 80 a 120 gramas.

Após o tratamento, os rizomas foram plantados em sulcos abertos a uma profundidade de 0,2 metros, distanciados de 0,3 metros e cobertos com uma fina camada de solo. O solo local apresentava as seguintes características: $\mathrm{pH}$ em $\mathrm{CaCl}_{2}$ de 6,0; M.O = 3,0 dag/kg; P (Mehlich-1) = $17,05 \mathrm{mg} \mathrm{dm}^{-3} ; \mathrm{K}=73,26 \mathrm{mg} \mathrm{dm}^{-3} ; \mathrm{Ca}=$ $2,34 \mathrm{mg} \mathrm{dm}^{-3} ; \mathrm{Mg}=1,02 \mathrm{mg} \mathrm{dm}^{-3} ; \mathrm{H}+\mathrm{Al}=$ $1,50 \mathrm{cmol}_{\mathrm{c}} \mathrm{dm}^{-3}$; V\% (porcentagem de saturação por bases) $=49,04 \% ; \mathrm{S}=9,71$ $\mathrm{mg} \mathrm{dm}^{-3}$; B (água quente) $=0,73 \mathrm{mg} \mathrm{dm}^{-3} \mathrm{e}$ $\mathrm{Cu}=2,73 \mathrm{mg} \mathrm{dm}^{-3}$.

A adubação e calagem foram realizadas conforme as recomendações do Manual de Recomendações de calagem e adubação para o estado do Espírito Santo $5^{\mathrm{a}}$ aproximação (PREZOTTI et al., 2007). 30 dias antes do plantio foi realizada a calagem elevando-se a saturação por bases para $70 \%$. No plantio, aplicou-se $20 \mathrm{~kg}$ de N/há, $400 \mathrm{~kg}$ de $\mathrm{P}_{2} \mathrm{O}_{5} /$ há e $40 \mathrm{~kg}$ de $\mathrm{K}_{2} \mathrm{O}$. As adubações de cobertura foram parceladas em 3 vezes, por ocasião das amontoas, aplicando-se 40 e $80 \mathrm{~kg}$ de $\mathrm{N}$ e $\mathrm{K}_{2} \mathrm{O}$, respectivamente em cada amontoa.

Para a irrigação utilizou-se o sistema de aspersão convencional, conforme a demanda da cultura. Foram realizadas três capinas juntamente com a amontoa aos 60, 120 e 150 DAP. A amontoa consistiu na retirada da terra da parte inferior do camalhão com o auxílio de um enxadão e sua distribuição na linha de plantio.

Quando se iniciou a emergência dos rizomas (14 DAP), foi iniciada a contagem do número de plantas que haviam emergido e, determinado o índice de velocidade de emergência, por meio da equação proposta por Maguire (1962):

$I V E=\frac{E_{1}}{N_{1}}+\frac{E_{2}}{N_{n}}+\cdots+\frac{E_{n}}{N_{n}} ;$
Em que: $E_{1}, E_{2}$ e $E_{n}=$ número de plântulas normais germinadas a cada dia; $\mathrm{N}_{1}, \mathrm{~N}_{2}$ e $\mathrm{N}_{\mathrm{n}}=$ número de dias decorridos da primeira à última contagem.

Para cada tratamento foi avaliado o número de caules aos 60 dias após o plantio (DAP). A variável foi determinada por intermédio da contagem do número de caules total de cada unidade experimental, dividindo pelo comprimento das duas fileiras úteis, obtendo-se assim o número de caules por metro linear.

A colheita foi realizada aos 210 DAP, por ocasião da senescência das folhas, com o auxílio de um enxadão. Os rizomas de gengibre são classificados de acordo com o peso em: classe de rizomas tipo extra (> 500 gramas); classe de rizomas tipo 1 (>250 gramas); classe de rizomas tipo 2 (> 150 gramas); e classe de rizomas tipo 3 (< 150 gramas).

Após a colheita e a secagem natural, os rizomas foram agrupados em apenas duas classes de acordo com o peso como: classe de rizomas tipo extra e classe de rizomas tipo 3 , conforme a classificação que vem sendo adotado por produtores da região de Morretes / PR (ELPO et al., 2008) e Santa Maria de Jetibá/ES. Após selecionadas, foram pesadas com a finalidade de obter a produtividade de rizomas para cada uma das classes avaliadas.

Os dados obtidos foram submetidos à análise de variância. Quando significativos, foram submetidos à análise de regressão por meio do método dos polinômios ortogonais. O modelo escolhido foi com base na significância do coeficiente de regressão, no coeficiente de determinação e do nível de significância. Todos os procedimentos foram realizados com o programa estatístico $\mathrm{R}$ Core Team versão 3.6.2 adotando-se um $\alpha$ de até 0,05 (R CORE TEAM, 2019). 


\section{RESULTADOS E DISCUSSÃO}

O tratamento com extrato de alho promoveu aumento de caules de gemas dos rizomas de gengibre. Pela análise de regresssão, verificou-se um comportamento quadrático, em que o maior número de caules por metro $(85,04)$ foi obtido com a exposição dos rizomas de gengibre ao extrato de alho por 8 horas e 55 minutos (Gráfico 1).

Gráfico 1: Número de caules por metro linear de rizomas de gengibre submetidos a diferentes tempos de exposição ao extrato de alho

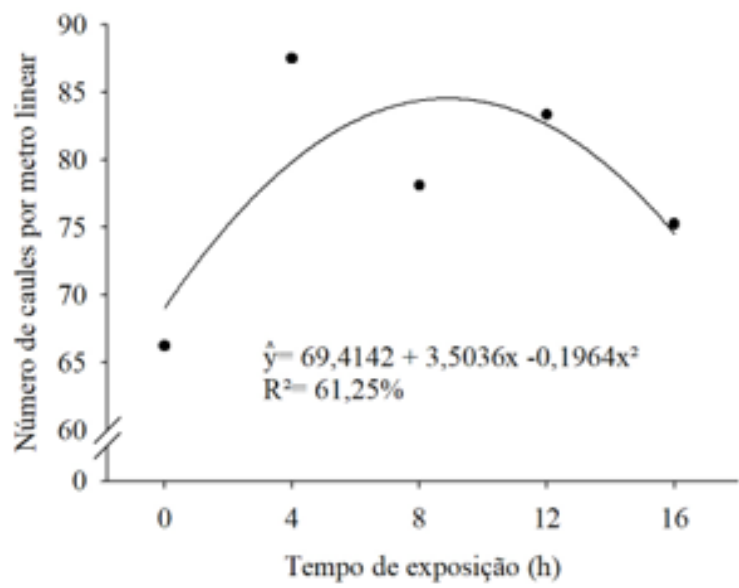

Fonte: elaborado pelo autor (2020)

Observa-se, pelo Gráfico 2, que a exposição dos rizomas de gengibre ao extrato de alho não promove a antecipação da emergência dos mesmos.

Na literatura, resultados semelhantes ao deste experimento já foram obtidos por outros autores, em que não verificaram diferença significativa para a variável índice de velocidade de emergência em sementes de Barriguda (Chorisia Glaziovii O. Kuntze), com o uso de diferentes concentrações de extrato de alho e erva-cidreira (Lippia alba) em relação ao tratamento-testemunha por (ARAÚJO et al., 2019) e não apresentou eficiência na quebra de dormência das videiras finas, no oeste paranaense (BUENO et al., 2017).
Gráfico 2: Índice de velocidade de emergência (IVE) de rizomas de gengibre submetidos a diferentes tempos de exposição ao extrato de alho

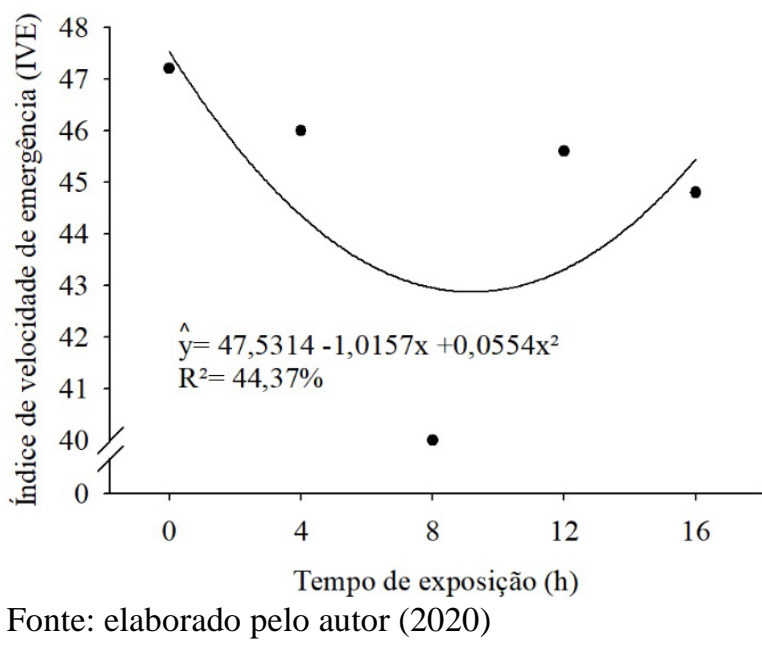

A ausência da resposta dos rizomas de gengibre aos tratamentos com extrato de alho, no que tange à velocidade de emergência, pode estar relacionado com a liberação insuficiente de compostos a base de enxofre presentes no alho, responsável na produção de metabólicos secundários, como a metionina.

A metionina desempenha um papel importantíssimo na produção de poliaminas (LEITE et al., 2012). Alguns dos efeitos fisiológicos da poliaminas podem ser citados, tais como o crescimento e divisão celular, embriogênese e calogênese, germinação e emergência de plantas, enraizamento e crescimento de plantas (SENA \& CASTRO, 1996).

De forma semelhante, a glutationa (GSH) é um composto reduzido de enxofre e altamente ativo sob condições de estresse, possuindo a capacidade de suprimir a inibição da germinação causada pelo ABA produzido durante o estresse abiótico (CHEN et al., 2012).

De acordo com Botelho e Müller (2007), Botelho (2007), e, também verificado no presente experimento, o extrato de alho mostrou-se efetivo para a superação da dormência, quando considerada a quantidade de brotos, devido às substâncias ativas presentes, que 
estão envolvidas na quebra de dormência de gemas. Entre os compostos, o dialil dissulfeto é um componente antioxidante, que, de acordo com Lanzotti (2006), pode exercer ação sobre $0 \quad \mathrm{O}^{-2}$ elevando a concentração de enzimas antioxidantes, dentre elas a catalase. A elevação dos níveis de catálise atua na redução da concentração de peróxido dentro das células auxiliando estas a sair da dormência.

Provavelmente esses compostos também atuariam pelo mesmo mecanismo proposto por Pinto et al. (2007), na quebra de dormência de plantas frutíferas de clima temperado, ou seja, através do estresse oxidativo, via acúmulo de $\mathrm{H}_{2} \mathrm{O}_{2}$, e este atuaria como um sinal químico, ativando diretamente a expressão de genes ou, indiretamente, responsável em exercer alterações metabólicas, detectadas por outras moléculas, que ativariam ou reprimiriam a expressão de genes responsáveis pela superação da dormência.

O melhor desempenho no número de caules com a aplicação de extrato de alho pode também estar relacionado com os compostos naturais encontrados a base de enxofre.

O enxofre é um constituinte dos aminoácidos cisteína, cistina e metionina e, portanto, das proteínas. Esses aminoácidos são precursores de outros compostos contendo enxofre, como coenzimas e produtos secundários. Como o enxofre é um constituinte estrutural desses compostos, atuaria como um grupo funcional, diretamente envolvido em reações metabólicas (RADY e ELYAZAL, 2014).

Tempos de exposição superiores a 8 horas e 55 minutos dos rizomas no extrato de alho proporcionou descrecimo no número de caules, conforme verificado na Figura 1. Esse fato, possilvemente ocorreu devido aos níveis endógenos de fitohormônios e metabólitos e/ou associado com as substâncias contidas no alho que poderiam estar em níveis satisfatórios para a brotação. Ou seja, o estímulo está associado aos tempos de exposição mais baixas, uma vez que longos períodos de exposição, podem exercer efeito fito tóxico em função da quantidade de compostos liberados, capaz de reduzir o número de caules.

A exposição dos rizomas de gengibre ao extrato de alho não proporcionou aumento da produção de rizomas tipo extra, com média geral de 53,52 t. ha ${ }^{-1}$ (Gráfico 3) e da classe de rizomas tipo 3 , apresentando média geral de 6,733 t.ha ${ }^{-1}$ (Gráfico 4).

Gráfico 3: Produção da classe de rizomas tipo extra dos rizomas de gengibre submetidos a diferentes tempos de exposição ao extrato de alho

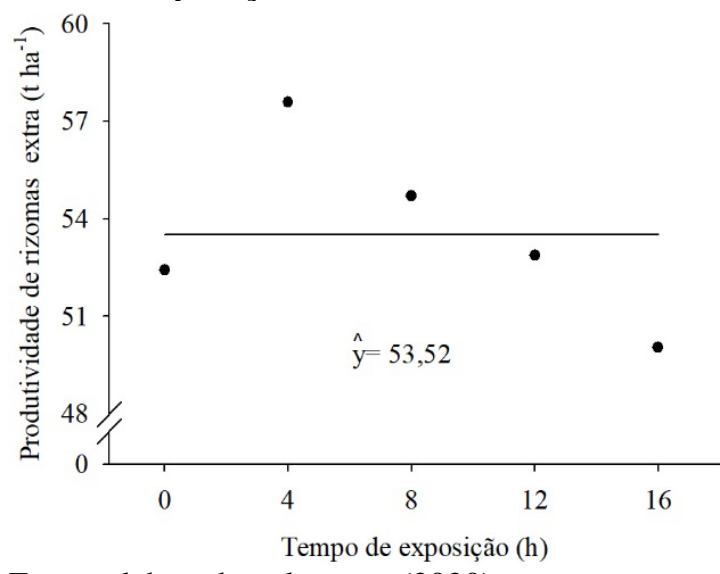

Fonte: elaborado pelo autor (2020)

Gráfico 4: Produção da classe de rizomas da classe tipo 3 dos rizomas de gengibre submetidos a diferentes tempos de exposição ao extrato de alho

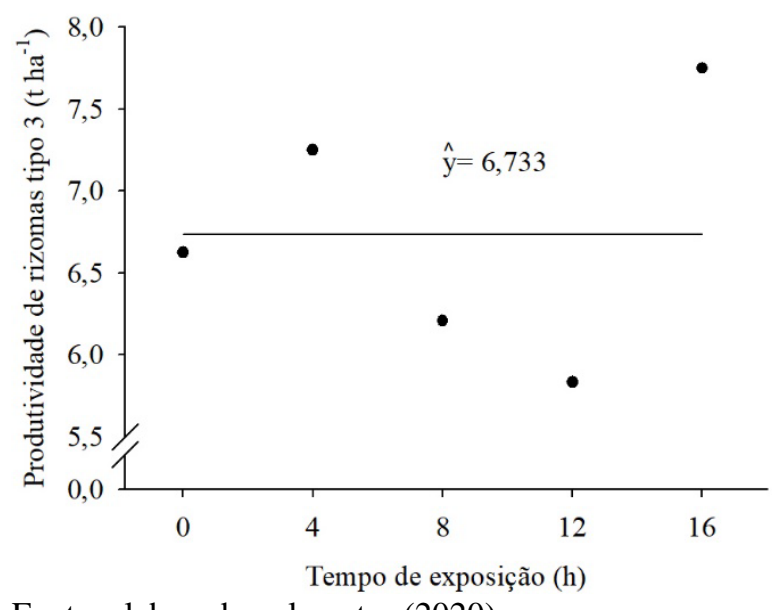

Fonte: elaborado pelo autor (2020) 


\section{CONCLUSÕES}

A exposição dos rizomas de gengibre ao extrato de alho, na concentração de $5 \%$, não teve efeito na antecipação da emergência dos mesmos. Porém, a exposição dos rizomas por 8 horas e 55 minutos promoveu um maior número de brotações dos rizomas.

A utilização do extrato de alho não proporcionou incremento na produção de rizomas das classes tipo extra e do tipo 3.

Os resultados apontam a necessidade de outros estudos, os quais podem contribuir para o incremento da utilização do extrato de alho na quebra da dormência de rizomas de gengibre.

\section{AGRADECIMENTOS}

À Fundação de Amparo à Pesquisa e Inovação do Espírito Santo (Fapes), pela bolsa cedida, e ao Instituto Federal do Espírito Santo (Ifes).

\section{REFERÊNCIAS}

ABBAS, M.S.; TAHA, H.S.; ALY, U.I.; EL-SHABRAWI, H.M.; GABER, E. In vitro propagation of ginger (Zingiber officinale Rosco). Journal of Genetic Engineering and Biotechnology (2011) 9, 165-172.

ARAÚJO, A. K. O.; GOMES, R. S. S.; SILVA, M. L. M.; SANTOS, A. M. S.; NASCIMENTO, L. C. Sanidade e qualidade fisiológica de sementes de Chorisia Glaziovii O. Kuntze tratadas com extratos vegetais. Ciência florestal, Santa Maria, v. 29, n. 2, p. 649-659, abr./jun. 2019. Disponível em:

http://www.scielo.br/pdf/cflo/v29n2/19805098-cflo-29-02-649.pdf. Acesso em: 30 jan. 2020.
BOTELHO, R. V. Efeito do extrato de alho na quebra de dormência de macieiras. Revista Brasileira de Fruticultura [on-line], vol.29, n.2, pp.403-405, 2007. Disponível em: https://www.scielo.br/scielo.php?pid=S010 0 -

29452007000200042\&script=sci_abstract \&tlng=pt. Acesso em 15 jan. 2020.

BOTELHO, R.V.; MÜLLER, M.M.L.

Extrato de alho como alternativa na quebra de dormência de gemas em macieiras cv.

Fuji Kiku. Revista Brasileira de

Fruticultura, Jaboticabal, vol.29, n. 1., 2007. Disponível em:

http://www.scielo.br/scielo.php?script=sci _arttext\&pid=S010029452007000100010. Acesso em 15 jan. 2020.

BOTELHO, R.V.; MAIA, A.J.; PIRES, E.J.P.; TERRA, M.M. Efeito do extrato de alho na quebra de dormência de gemas de videiras e no controle in vitro do agente causal da antracnose (Elsinoe ampelina Shear). Revista Brasileira de Fruticultura, Jaboticabal, vol.31 n.1. 2009. Disponível em: http://www.scielo.br/scielo.php?script=sci _arttext\&pid=S010029452009000100015. Acesso em: 30 jan. 2020.

THOMAS FAVARETTO BUENO, T.F.; VILLA, F.; ROSA, D.D.; STUMM, D.R. Rev. Ceres, Viçosa, v. 64, n.4, p. 426-432, jul/ago, 2017. Disponível em:

http://www.ceres.ufv.br/ojs/index.php/cere s/article/view/4324/2347. Acesso em: 09 out. 2020.

CARMO, C.A.S.; BALBINO, J.M.S. Gengibre. - Vitória, ES: Incaper, 2015. 192 p. il.

CEASA (Centrais de abastecimento do Espírito Santo S.A.). Filtro procedência por produto/variedade. [S.I] [2019?]. Disponível em: http://200.198.51.71/detec/filtro_prdvar_es 
/filtro_prdvar_es.php. Acesso em: 08 out. 2020.

CHEN, J. H.; JIANG, E.; HSIEH, H.; CHEN, C.; CHIEN, H.; HSIEH AND T. LIN. 2012. Drought and salt stress tolerance of an Arabidopsis glutathione STransferase U17 knockout mutant are attributed to the combined effect of glutathione and abscisic acid. Plant Physiol., 158: 340-351.

ELPO, E.R.S.; NEGRELLE, R.R.B.; RUCKER, N.G.A. Produção de gengibre no município de Morretes, PR. Scientia Agraria, Curitiba, v.9, n.2, p. 211-217, 2008. Disponível em:

https://revistas.ufpr.br/agraria/article/view/ 10971/8198. Acesso em: 29 jan. 2020.

EMBRAPA. Aditivos. Embrapa trigo. n. 56. Passo Fundo, RS. 2006. Disponível em:

http://www.cnpt.embrapa.br/biblio/do/p_d o56_5.htm . Acesso em: 08 out. 2020.

FIDELIS, L. Crescimento de mais de 200\% nas exportações de gengibre. Safra ES. 2018. Disponível em:

https://www.safraes.com.br/exportacoes/cr escimento-mais-200-nas exportacoesgengibre. Acesso em: 29 jan. 2020.

GERMCHI, S.; BEHROOZI, G.; BADRI, S. Effect of Thiourea on Dormancy Breaking and Yield of Potato (Solanum Tuberosum L.) Minitubers Marfona cv. in Greenhouse. International Conference on Environmental and Agriculture

Engineering - IPCBEE vol.15 (2011).

Disponível em

http://www.ipcbee.com/vol15/4-

U00028.pdf. Acesso em: 28 jan. 2020.

INDEXBOX. Global Ginger Market 2019 - U.S. Imports Increases Robustly, Turning The Country Into The Most Promising Market. August 9th, 2019. Disponível em https://www.globaltrademag.com/global- ginger-market-2019-u-s-imports-increasesrobustly-turning-the-country-into-themost-promising-market/. Acesso em: 27 jan. 2020.

LANZOTTI, V. The analysis of onion and garlic. Journal of Chromatography A, Maryland Heights, v.12, p. 3-22,2006. Disponível em: https://pubmed.ncbi.nlm.nih.gov/16388813 / . Acesso em: 28 jan. 2020.

LEITE, G.A.; CARVALHO, C.A.C.; WALLACE E. DE S. FREITAS, W.E.S.; DANTAS, J.I.A.; PONTES, C.A.; FERNANDES, P.L.O. A ação das poliaminas na maturação e senescência de frutos. ACSA - Agropecuária Científica no Semiárido, v.8, n.4, p.08-21, out - dez, 2012. Disponível em:

https://www.researchgate.net/publication/2 82859201_A_acao_das_poliaminas_na_m aturacao_e_senescencia_de_frutos. Acesso em: 11 jun. 2020.

MAGUIRE, J. D. Speed of germinationaid in selection and evaluation for seedling emergence vigor. Crop Science, v. 2, n. 2, p. 176-177, mar. 1962.

PINTO, M.; LIRA, V.; UGALDE, H.; PÉREZ, F. Fisiologia de la latência de las yemas de vid: hipótesis actuales. Santiago, p. 1- 16, 2007. Disponível em: https://www.researchgate.net/profile/Franc isco_Perez11/publication/228660332_Fisio logia_de_la_latencia_de_las_yemas_de_vi d_hipotesis_actuales/links/559be52508ae0 035df2338c6.pdf. Acesso em 16 jan. 2020.

PREZOTTI, Luis Carlos; GOMES, José Antônio; DADALTO, Gilmar Gusmão; OLIVEIRA, José Adilson. Manual de recomendação de calagem e adubação para o Estado do Espírito Santo. $5^{a}$. aproximação. Vitória (ES): SEEA/INCAPER/CEDAGRO, 2007.

EL-YAZAL, M.A.S.; EL-YAZAL, S.A.S.; RADY, M.M. Exogenous dormancy- 
breaking substances positively change endogenous phytohormones and amino acids during dormancy release in 'Anna' apple trees. Plant Growth Regul, v.72, p.211-220, 2014.

R Core Team (2019). R: A language and environment for statistical computing. $\mathrm{R}$ Foundation for Statistical Computing, Vienna, Austria.

SENA, J.O.A.; CASTRO,

P.R.C. Poliaminas: aspectos fisiológicos e importância para as plantas. 1996, 41p. (Apontamentos, 46). 